\title{
A mudança de governo no Brasil e os efeitos nas políticas de Educação Superior: uma análise preliminar
}

\author{
LUIS ENRIQUe AgUiLAR* \\ Eliacir Neves França*
}

*UNICAMP - Departamento de Políticas, Administração e Sistemas Educacionais

(DEPASE).

**Universidade Estadual de Londrina (UEL). Departamento de Educação.

\begin{abstract}
Resumo
O golpe parlamentar levado a cabo no Brasil em 2016 resultou no impeachment da presidenta Dilma Rousseff e na hegemonia de um grupo político alinhado aos postulados da extrema-direita. A partir de então as políticas públicas passam por ajustes ultraliberais que levaram ao desmonte de expressiva parte dos direitos sociais com o apoio do Congresso Nacional, uma vez que tal feito foi possível graças à aprovação da Emenda Constitucional. Em 2018 toma posse no cargo de Presidente da República Jair Messias Bolsonaro, intensificando as ações que vinham sendo executadas por seu antecessor Michel Temer. Seu governo é marcado pela instabilidade política e por crises de grande envergadura. No campo das políticas educacionais, a agenda é direcionada para o desmonte da esfera pública e para a hipervalorização do setor privado. Este texto tem como objetivo discutir ações empreendidas no primeiro ano do Governo Bolsonaro no campo da Educação Superior. Para tanto, abordaremos a tentativa de criar a "Lava-Jato da Educação" e o corte de verbas das universidades federais. Podemos afirmar que o escopo e o curso de ação do Governo Bolsonaro são norteados pelas demandas e relações que se estabeleceram entre o Estado e o mercado.
\end{abstract}

Palavras chave: Educação Superior, políticas educacionais, ultraliberalismo, análise de política. 


\section{El cambio de gobierno en Brasil y los efectos en las políticas de educación superior: un análisis preliminar}

\section{Resumen}

El golpe de estado en Brasil, en 2016 resultó en la destitución de la presidenta Dilma Rousseff y en la hegemonía de un grupo político alineado a los postulados de la extrema derecha. Desde entonces, las políticas públicas, con el apoyo del Congreso Nacional, han sufrido ajustes ultraliberales que han llevado al desmantelamiento de una parte significativa de los derechos sociales, lo que sucedió debido a la aprobación de la Enmienda Constitucional. En 2018 asumió el cargo de Presidente de la República Jair Messias Bolsonaro, quien intensificó las acciones que ya se estaban llevando a cabo. Su gobierno está marcado por la inestabilidad política y las grandes crisis. En el campo de las políticas educativas, la agenda se dirige hacia el desmantelamiento de la esfera pública y la sobrevaloración del sector privado. Este texto tiene como objetivo discutir las acciones tomadas el primer año de gobierno de Bolsonaro en el campo de la educación superior. Con este fin, abordaremos el intento de crear la "Lava-jato da Educação" ("Operación auto-lavado de la Educación"), y el recorte de fondos de las universidades federales. Podemos afirmar que el alcance y el curso de acción del gobierno de Bolsonaro se guían por las demandas y las relaciones que se han establecido entre el Estado y el mercado.

Palabras clave: Educación Superior; políticas educativas; ultraliberalismo; análisis de políticas.

\section{The Change of Brazil's Government and the Effects on Higher Education Policies: A Preliminary Analysis}

\section{Abstract}

The coup d'État that was carried out in Brazil in 2016 produced the President Dilma Rousseff's impeachment and the hegemony of a political group aligned with the postulates of the extreme right. From that point on, public policies have undergone ultraliberal adjustments that have led to the dismantling of a significant part of social rights with the support of the National Congress, since this was possible thanks to the approval of the Constitutional Amendment. In 2018, Jair Messias Bolsonaro took office as President of the Republic, intensifying the actions that were being carried out. His government has been marked by political instability and major crises. In the field of educational policies, the agenda is directed towards the dismantling of the public sphere and the overvaluation of the private sector. This study aims to discuss the actions taken in the first year of the Bolsonaro's government in the higher education field. With this objective, we will attempt to create the "Lava-Jato da Educação" and the cut of funds from federal universities. We can affirm that the scope and action course of the Bolsonaro's government are guided by the demands and relations that have been established between the State and the market.

Keywords: higher education, educational policies, ultraliberalism, policy analysis. 


\section{Introdução}

Este artigo foi escrito num contexto de gravíssima crise sanitária e política que revelou um ineditismo pela degradação no tratamento das instituições democráticas, essa foi a primeira vez que o fenômeno aconteceu no regime democrático, noutros momento vivíamos uma ditadura.

O regime democrático, necessariamente, comporta divergências de muitas ordens, das quais pode resultar o fortalecimento da democracia e a estabilidade das instituições democráticas. Essas:

[...] são instituições políticas num sentido amplo; elas têm uma relação direta e reconhecível com os principais temas da política: a tomada de decisões que são obrigatórias num dado território, os canais de acesso a essas decisões e às funções de governo que possibilitam tomá-las, e a moldagem dos interesses e identidades que reivindicam acesso a esses canais e decisões. (...) algumas instituições políticas são organizações formais pertencentes à rede constitucional de uma poliarquia; estas incluem o Congresso, o Judiciário, e pelo menos mais de um partido político. Outras, como eleições limpas, têm uma continuidade organizacional intermitente, mas nem por isso são menos indispensáveis. (O’Donnell, 1991, p. 27)

Grosso modo falando, neste momento histórico, as instituições democráticas no Brasil se omitiram ou, no mínimo, se silenciaram ante a forma de administração do Estado empreendida por Jair Messias Bolsonaro, presidente eleito em 2018. Suas ações e posturas demonstram a emergência de uma democracia delegativa. Esta, segundo O'Donnell (1991), se caracteriza por uma forma de administrar no âmbito do Executivo, onde aquele que for eleito crê possuir o direito e a obrigação de decidir, de acordo com seu entendimento pessoal, o que é melhor para a res publica durante o periodo que durar o seu mandato. Esta é a postura que vemos como enfraquecedora, e degradadora das instituições da democracia.

Sustentado por um discurso ultraconservador, pautado em valores como família, religião, armamento da população, eliminação dos comunistas e da corrupção - cujo mote era o ataque ao projeto de Estado implantado pelos governos do PT -, foi eleito Presidente da República Jair M. Bolsonaro em 2018.

Noutras palavras, Bolsonaro chegou no poder graças a um discurso calcado no pensamento conservador, à leitura de um mundo pregado por determinados grupos religiosos, e ao pensamento colonialista que deprecia negros, homossexuais, e populações indígenas sem qualquer constrangimento. Os recursos para garantir sua eleição foram o uso de tecnologias digitais para difusão de fake news e o tradicional, parcial e alienador discurso armado nos grandes veículos de comunicação que produzem e reproduzem os interesses da elite financeira.

Uma característica da gestão de Bolsonaro é utilizar a rede social Twitter para anunciar medidas e políticas de seu governo, uma prática, segundo nosso entendimento, que denota uma postura populista e antidemocrática uma vez que este meio restringe a fala àqueles que utilizam esta rede social. 
Não vemos debates democráticos no "Brasil de Bolsonaro". Como exemplo se têm os ataques à imprensa, ao Supremo Tribunal Federal (STF), ao Parlamento, a grupos indígenas, quilombolas e demais minorias, que são frequentes por parte do Presidente da República, seus filhos e membros do primeiro escalão do governo, sem que o Judiciário, grosso modo falando, cumpra seu papel. A disseminação de fake news por esse mesmo grupo também é outro fator que contribui na degradação das instituições democráticas.

Sob nosso entendimento, Bolsonaro se vê "sujeito apenas ao julgamento dos eleitores nas eleições seguintes. (...) Diante disso, todo tipo de controle institucional é considerado um obstáculo injustificado; portanto, os líderes delegados tentam subordinar, suprimir ou cooptar essas instituições" (O’Donnell, 2009, p. 1), como temos acompanhado no Brasil desde 2016, quando um golpe parlamentar destituiu a presidenta Dilma Rousseff. Tal processo revelou uma descomunal aliança entre as forças políticas, midiáticas e judiciais, que levaram o atual grupo político ao poder. Tal instrumento foi utilizado em outros momentos da história do país com o mesmo propósito: alternar o grupo político no poder. O processo do impeachment contribuiu sobremaneira no movimento de degradação das instituições democráticas.

Demarché parte dos membros do Legislativo, Judiciário, intelectuais e jornalistas que têm envidado esforços para combater a visão de golpe parlamentar, no limite deste texto, onde se focou a forma como o processo do impeachment que foi conduzido a um desafio que requereu "articular e tornar compreensível a complexa rede de interesses impessoais que, a exemplo do teatro de marionetes, prende os fios que permitem criar o drama reproduzido pelas pessoas no palco da vida" (Souza, 2016, p. 11).

Concordamos com Souza (2016, p. 12) quando afirma que "o esclarecimento de qualquer fato contemporâneo depende da reconstrução de sua perspectiva histórica. O presente não se autoexplica sem que o passado nos desvende sua gênese". Então, decidimos começar nossa reflexão no Golpe de 2016, uma farsa forjada pelas elites financeiras ${ }^{1}$ cujo mote foi a corrupção seletiva afinal do discurso que sustentou o movimento que levou ao impeachment da presidenta Dilma Rousseff, que estava embasado, em grande medida, na cobertura feita pelos grandes veículos ${ }^{2}$ de comunicação sobre a ação coordenada pela Polícia Federal e pelo Ministério Público Federal, que visava combater a corrupção, e que acabou focando os governos do Partido dos Trabalhadores (PT) no âmbito da "Operação Lava-Jato"3.

Assistimos um contundente movimento de desmoralização e ataque ao projeto de Estado encampado por Luís Inácio Lula da Silva e Dilma Rousseff, travestido de ação de combate à corrupção utilizando a "Operação Lava-Jato. Projeto contrário à concepção de Estado da elite financeira que, historicamente, vampiriza a nação e se mantém hegemônica graças à construção de uma racionalidade específica, calcada de uma ideia de raça "que expressa a experiência básica da dominação colonial” (Quijano, 2005, p. 121).

Grande parte da população brasileira foi convencida, pelo discurso veiculado nos meios de comunicação, de que os responsáveis pelas mazelas de suas vidas e do país eram as ações dos dois governantes do PT que ocupa- 
ram a presidência da República no periodo de 2003 a 2016. Neste periodo, foi implementada uma política de combate à fome e à pobreza, uma de criação de emprego e renda, e uma de inserção das camadas mais empobrecidas da população no Ensino Superior, apenas para citar alguns exemplos. A grande contradição esteve no fato de que, boa parte das pessoas beneficiadas por estas políticas, assumiram o discurso golpista juntamente com a parcela expressiva da classe média.

Uma das hipóteses que pode explicar este fenômeno está no fato de que, no Brasil, o colonialismo que forjou a sociedade brasileira, e a fez refém do euro-centrismo, faz parte da população brasileira, ainda hoje, e é refém de um discurso racista, sexista e subserviente: terreno fértil para o discurso golpista calcado em valores morais e religiosos que pregavam o combate à corrupção.

O Golpe de 2016 foi perpetrado por via "democrática" e "legal" uma vez que o Congresso Nacional votou e se decidiu pelo impeachment da presidenta Dilma Rousseff, que se fez com base no Relatório do Tribunal de Contas da União (TCU), de 2014, e que apontava irregularidades na execução orçamentária de 2014. O ponto central que sustentou essa rejeição foram as chamadas "pedaladas fiscais" ${ }^{4}$ práticas comuns nos governos anteriores e posteriores ao do governante do Partido dos Trabalhadores (PT).

A ressignificação do conceito do democrático, ilegal ou inconstitucional neste momento histórico, revela uma peculiaridade do Brasil: sua classe política, seus grupos midiáticos e seus atores custódios da justiça e da Constituição. É por este motivo que sustentamos o entendimento de que se tratou de um Golpe de Estado, leitura que não é leviana. É patente o fato de que um grupo político, um midiático e outro judicial valeram-se de práticas ardilosas para cumprir uma tese feita após a vitória de Dilma Rousseff, em 2014, pelo senador do Partido da Social Democracia Brasileira (PSDB) José Aníbal, quem afirmou, à época, parafraseando Carlos Lacerda sobre a eleição de Getúlio Vargas: "Não pode ser candidata. Se for, não pode ser eleita. Se eleita, não pode tomar posse. Se tomar posse, não pode governar". Este é o conceito de Golpe que contrasta com a argumentação de levar adiante uma denúncia, de lhe dar enquadramento constitucional e de gerar clamor popular pelo fim de um governo eleito numa articulação entre a elite financeira, políticos, conglomerados midiáticos e juízes.

Os fatos aqui analisados sugerem que, no Brasil, o regime democrático carece de fortalecimento. Afinal, que as democracias e o Estado sejam frágeis na América Latina é um consenso ao que lamentavelmente chegamos nestas últimas quatro décadas. Isso tem relação direta com os ciclos de aproximação e distanciamento das concepções neoliberais do Estado quando grupos progressistas e conservadores se revezaram no poder na região (Aguilar, 2017).

Apontar a fragilidade da democracia nos países da região implica em demarcar nossa posição. Entendemos que "uma boa democracia, ou melhor, uma democracia de qualidade, essa ordenação institucional estável que através de instituições e mecanismos que funcionam corretamente, realiza a liberdade e a igualdade dos cidadãos" (Morlino, 2017, p. 5. Tradução nossa). 


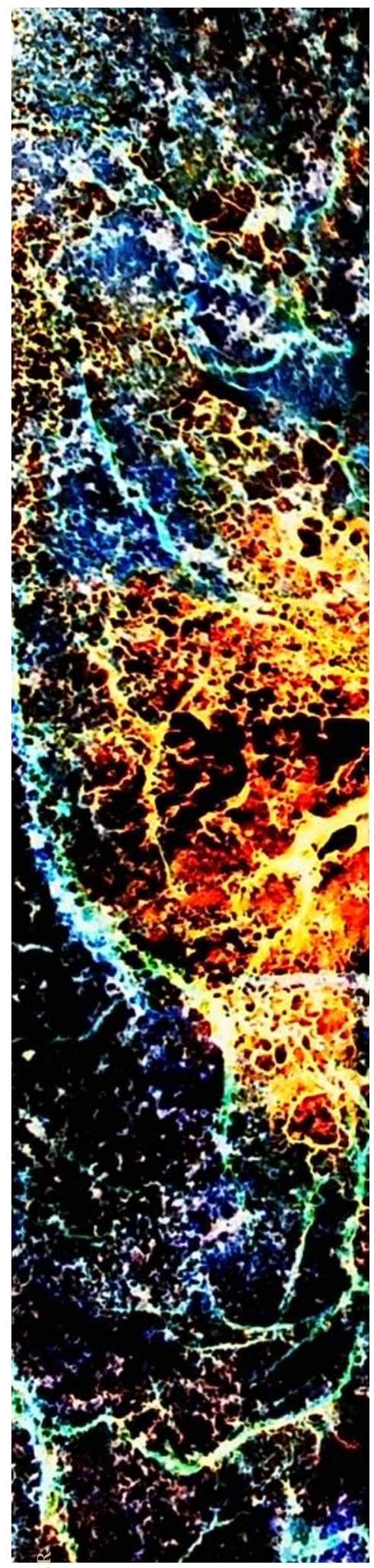

Lamentavelmente, neste momento histórico, estamos bastante distantes de vivermos uma ou em uma democracia forte ou de qualidade. Um exemplo que ilustra nossa inferência são os ataques por parte de um grupo de civis, apoiadores do presidente Jair Bolsonaro, ao Supremo Tribunal Federal (STF). Onde, pese a gravidade de tal ação, não houve nenhuma manifestação do chefe do Executivo Federal no sentido de reprovar a situação. Ao contrário, de certa forma apoiou os atos. Podemos citar, também, a dimensão de retrocesso nas conquistas sociais e econômicas que os governos progressistas obtiveram desde o início dos anos 2000.

É inegável que os ciclos de governos conservadores e progressistas produziram mudanças no Estado e na concepção do seu papel na economia, e que a cidadania tem usufruído elevando sua intensidade e incorporado conquistas. Entretanto, o impeachment de Dilma Rousseff inauguraria um processo de retrocesso descomunal, cuja viabilização foi possível também pela aprovação da Emenda Constitucional No. 95 de 15 de dezembro de 2016, também conhecida como a Emenda do Teto dos Gastos Públicos, que estabeleceu um limite para despesas primárias por 20 anos. Isso significa que, durante duas décadas, haveria um percentual definido (independentemente do aumento da arrecadação do Estado) para investimento em áreas como Educação, Saúde, Saneamento e Segurança, por exemplo. Estes são os chamados direitos sociais, que foram consagrados na Constituição de 1988.

Dentre os direitos sociais, a Educação foi a área mais afetada por esta Emenda uma vez que foi anulado o percentual constitucional de investimento na área: $25 \%$ nas receitas de estados e municípios, e $18 \%$ na União. O Plano Nacional de Educação (PNE), aprovado em 2011, também foi prejudicado uma vez que os recursos públicos estiveram excessivamente limitados.

Este é o cenário mais amplo onde se localiza a análise que pretendemos apresentar neste texto, qual seja, sobre as políticas do Governo Bolsonaro para a Educação Superior, focando duas ações pontuais. 


\section{O Governo Bolsonaro e a Educação Superior: uma análise preliminar}

Sob o nosso ponto de vista, neste momento histórico, temos no Brasil um projeto de governo que visa o desmonte da educação pública com o objetivo claro de abrir espaço para a iniciativa privada atuar sem qualquer controle ou ressalva legal. Um elemento que sustenta nossa afirmação é que, em pouco mais de um ano de governo, Bolsonaro nomeou quatro pessoas para ocupar o cargo de Ministro da Educação (MEC), todos com um discurso alinhado ao setor privado, que atua na educação nacional desde meados da década de 1990, e/ou com relação estreita com os think tanks que atuam na área. O primeiro ministro nomeado permaneceu no cargo por três meses e uma semana, o segundo ficou quatorze meses, o terceiro ficou apenas cinco dias, e o quarto foi nomeado recentemente.

Em dezessete meses do Governo Bolsonaro tem sido comum o ataque à autonomia universitária consagrada na Constituição de 1988, perseguições a educadores, uma postura antissindical, o autoritarismo e medidas antidemocráticas, práticas que aproximaram o MEC no conservadorismo de extrema-direita.

No caso da autonomia universitária, foi publicado o Decreto No. 9.794, em 14 de maio de 2019, que dispõe, sobre a nomeação para cargos de direção, que são de competência exclusiva do Presidente da República sem a referenda ministerial. Este documento legal levou a nomeação de Reitores das Universidades Federais e Institutos Federais a estar de acordo com a preferência do chefe do Executivo Federal, em desrespeito à eleição democrática ocorrida no interior de cada universidade, porque, tradicionalmente, os reitores que são eleitos encaminham-se uma em lista tríplice ao presidente, que nomeia o primeiro da lista, ou seja, o candidato eleito.

Devido à necessária falta de distanciamento histórico para procedermos a uma análise mais profícua acerca das políticas do Governo Bolsonaro para a Educação Superior, decidimos focar nossa reflexão em ações pontuais: a tentativa de criar a "Lava-jato da Educação" e o corte de verbas das universidades federais.

O primeiro Ministro da Educação nomeado por Jair Bolsonaro, Ricardo Vélez-Rodríguez, anunciou, já no início de seu mandato, que procederia às investigações de medidas adotadas em gestões anteriores. O projeto foi nomeado pelo Ministro de "Lava-Jato da Educação", em referência à "Operação Lava-Jato", acima referenciada, e que estabeleceu medidas de combate à corrupção na área da educação.

A fim de executar o projeto foi celebrado um protocolo de intenções entre os ministros da Educação e da Justiça, Sérgio Moro, e da Controladoria-Geral da União, Wagner Rosário, além do advogado-geral da União, André Mendonça. Esse documento transforma o projeto numa ação interministerial. O diretor-geral da Polícia Federal (PF), Maurício Valeixo, também participou na reunião, acordando que em "casos extremos" a PF participaria na operação (Saldaña, 2019, p. 1).

Imediatamente o Presidente da República publicou em sua conta do Twitter a mensagem: 
Muito além de investir, devemos garantir que os investimentos sejam bem aplicados e gerem resultados. Partindo dessa determinação, o ministro professor Ricardo Vélez apurou vários indícios de corrupção no âmbito do MEC em gestões passadas. Daremos início à 'Lava-Jato da Educação. (Bolsonaro, 2015, tuit)

Tal medida foi qualificada pelo presidente como uma das prioridades de seu governo.

A assessoria de imprensa do MEC enviou nota à imprensa informando que a equipe que acabara de tomar posse havia identificado favorecimentos indevidos no Programa Universidade para Todos (ProUni): e desvios no Programa Nacional de Acesso ao Ensino Técnico e Emprego (PRONATEC), envolvendo o sistema $S^{5}$, a concessão ilegal de bolsas de ensino a distância e as irregularidades em universidades federais durante a gestão do então Ministro da Educação, Fernando Haddad - candidato à Presidência da República pelo PT em 2018.

Depois da demissão de Ricardo Vélez Rodriguez, foi nomeado Ministro da Educação Abraham Weintraub, quem arquivou a "Lava-Jato da Educação".

O corte de verbas nas universidades federais aconteceu na gestão de Abraham Weintraub por meio do Decreto No. 9.741 do 29 de março de 2019. Nesse instrumento legal, quando consideramos todas as universidades, o corte é de R\$ 1,7 bilhão, o que representa $24,84 \%$ dos gastos não obrigatórios (chamados de discricionários) e 3,43\% do orçamento total das federais.

De acordo com a nota publicada pela assessoria de imprensa, a decisão foi tomada devido à diminuição na arrecadação de impostos. Sob o nosso ponto de vista, a decisão pelo corte de verbas é fruto de um posicionamento ideológico de ataque às universidades federais. Nossa leitura se sustenta no fato de que o ministro, reiteradas vezes, tem tecido considerações desabonadoras a respeito dos docentes e estudantes destas instituições.

Na legislação brasileira, uma ação como a disposta no documento legal acima referido é denominada "contingenciamento"6 e atinge as despesas não obrigatórias, também chamadas de discricionárias. Essas são divididas, segundo a legislação, em duas categorias: a) gastos com custeio ou despesas correntes, utilizados para manter o funcionamento das universidades (contas de luz, de água, bolsas acadêmicas, insumos de pesquisa, compra de equipamentos básicos para laboratórios e pagamento de funcionários terceirizados); e b) despesas de investimento ou de capital (obras nas universidades e a compra de equipamentos).

Em 30 de abril de 2019, em entrevista ao jornal O Estado de S. Paulo, o ministro atacou pontualmente à Universidade Federal Fluminense, à Universidade Federal da Bahia e à Universidade de Brasília, afirmando que o corte se deveu ao baixo desempenho e a "balbúrdia". Textualmente afirmou: "Universidades que, em vez de procurar melhorar o desempenho acadêmico, estiverem fazendo balbúrdia, terão verbas reduzidas. A lição de casa precisa estar feita: publicação científica, avaliações em dia, estar bem no ranking” (Agostini, 2019, p. 2) 
A União Nacional dos Estudantes (UNE), a Associação Nacional dos Pós-Graduandos (ANPG) e a União Brasileira dos Estudantes Secundaristas (UBES), ajuizaram a ação no Superior Tribunal de Justiça (STJ) pugnando pela suspensão do corte de verbas das universidades federais (Mandado de Segurança No. 25.174 - DF (2019/0125834-8)). O argumento central, embasado no Decreto No. 9.741 do 29 de março de 2019 , foi o prejuízo que tal medida imporia às universidades.

O Relator do processo foi o Ministro Sérgio Kukina que negou o pedido nos termos que segue:

No caso, os argumentos das impetrantes, assim parece, baseiam-se, sobretudo, em entrevistas concedidas pela autoridade apontada como coatora, restando enfraquecida, nessa medida, a plausibilidade das alegações veiculadas na exordial, tornando-se inócua, em consequência, a perquirição em torno da alegada presença do perigo da demora. Ante o exposto, indefiro o pedido de concessão de liminar, sem prejuízo de, em novo contexto, reexaminá-lo adiante. (Despacho, 2019, p. 8)

Chamamos a atenção para o fato do magistrado não ter mencionado o documento legal em seu despacho: a que focou fatos tangenciais constantes da exordial decidindo de forma parcial, já que não abordou o cerne da ação que foi o Decreto que determinava o corte de verbas. Este posicionamento tem sido, lamentavelmente, comum no Brasil por parte dos membros do Judiciário.

Aproximadamente sete meses depois da publicação do Decreto que cortou verbas das universidades federais, o ministro da Educação anunciou a liberação das mesmas sem oferecer uma explicação contundente ao respeito da decisão, apenas afirmou que realizou um remanejamento de verbas no Ministério.

A rotatividade de ministros para a pasta da Educação, o movimento de descontinuidade das políticas, os constantes escândalos, entre outros, permitiram a inferência de que a política definida para a educação no Governo Bolsonaro é a decisão explícita de conceder este ministério à denominada ala religiosa de seus apoiadores. A influência da ala religiosa na gestão dos ministros da Educação se caracteriza pelo discurso que nega a ciência, subordinando-a às concepções ultraconservadoras que embasam o discurso de pastores e lideranças das principais igrejas

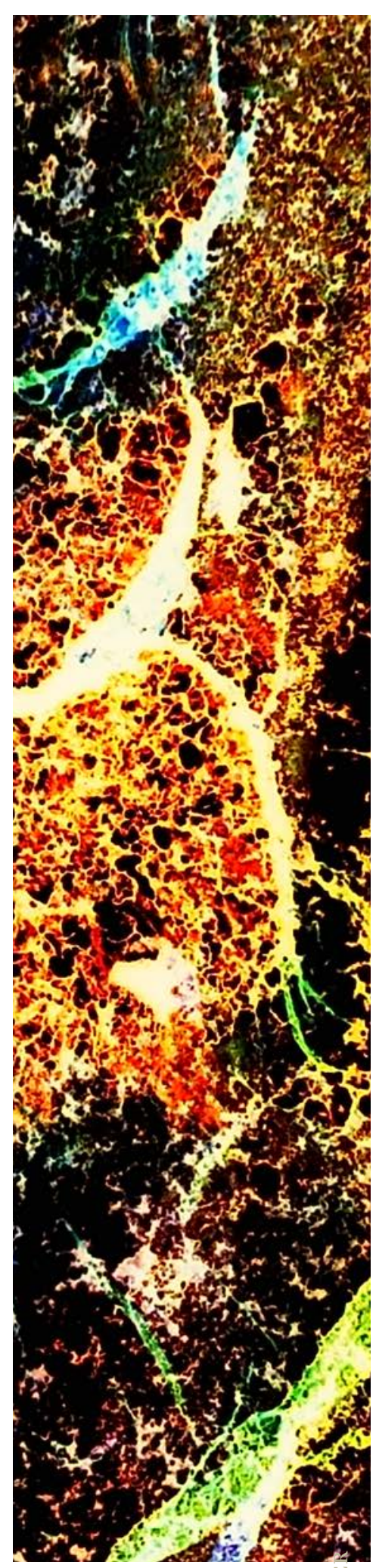


evangélicas que apoiam o governo de Bolsonaro. $\mathrm{O}$ ataque ao valor do conhecimento da ciência por oposição do dogmatismo religioso, encontrou eco nos ministros da Educação que cortaram verbas das agências nacionais de fomento sob o argumento de que nesses centros acadêmicos de excelência se produzia balbúrdia, e frequentemente misturavam esses ataques em discursos homofóbicos, sexistas, racistas e anticomunistas, onde o objetivo principal era associar conhecimento, opção sexual, e política, à cor da pele e à transgressão de mandados bíblicos.

Ao finalizar esta análise preliminar, o Governo Bolsonaro tinha indicado o pastor presbiteriano Milton Ribeiro como ministro da Educação, e nomeou 12 novos membros do Conselho Nacional da Educação de um total de 24 integrantes. Sete desses nomeados são evangélicos, e não se renovou a participação dos representantes das Secretarias Estaduais de Educação e dos Secretários Municipais de Educação. O ministro Ribeiro afirmara que nas universidades se ensinava sexo sem limites.

Se o ministro Weintraub, que antecedeu o atual ministro, foi alvo de denúncias por ataques à ciência, às políticas de cotas, ao conceito de povos indígenas, entre outros tantos desmanes: o ministro Vélez Rodríguez, que o antecedeu, também mantinha uma linha semelhante. Isto é a política definida para a pasta da Educação, que é ultraconservadora e religiosa com discursos reacionários, preconceituosos e dogmáticos de fluída circulação nas redes sociais de fiéis ligados às igrejas apoiadoras. Inferimos, assim, que se tem um novo cenário de construção da política educacional nacional onde a opção pelo discurso religioso e dogmático tem se convertido no principal argumento para definir o rumo da política e desconstruir as conquistas de décadas: está se redefinindo a relação do Ministério com as Redes Estaduais e Municipais, está se definindo o conceito de ciência no currículo, está se definindo o conceito de educação do cidadão calcado nos fundamentos ultra conservadores da direita religiosa. Um fato absolutamente patético, do ponto de vista da análise acadêmica nas mudanças na educação brasileira, se vincula à ação de movimentos e partidos políticos que se alinharam no slogan escola sem partido, que ataca o pensamento crítico e denuncia a manipulação ideológica que estaria acontecendo nas escolas, levando aos alunos a desvios sexuais e políticos e, a se organizarem para introduzir estas ideias no texto da Lei de Diretrizes e Bases da Educação Nacional -LDB. O patético está em que o projeto de alteração da LDB foi apresentado ao presidente Bolsonaro pelo deputado federal Alexandre Frota, ator de pornografia.

\section{Considerações finais}

Diante da discussão aqui posta, entendemos que é fundamental retomar o pensamento crítico como forma de contribuir no fortalecimento, a manutenção e a ampliação do direito à educação de matriz emancipatória.

Podemos afirmar que o escopo e o curso de ação do Governo Bolsonaro foram norteados pelas demandas e relações que se estabeleceram entre o Estado e o mercado, por uma estratégia que foi, e que é, marcadamente ofensiva sobre o significado e o valor da ciência para a política e a socieda- 
de, e, sobretudo, do valor da política científica ancorada no valor das instituições de Educação Superior como produtoras do conhecimento.

O falso debate sobre a ideologização das universidades e os cotidianos insultos, via redes sociais, ao trabalho científico, se converteu em estratégia e curso de ação de política educacional, pois, por meio da mesma via do insulto, por exemplo: a) deixaram de prover recursos para as agências nacionais de fomento da pesquisa; b) instituições de reconhecida trajetória na pesquisa científica e produção de conhecimento perderam resultados por cortes nas verbas de fomento a projetos; c) suspensão e corte de bolsas de pós-graduação; d) a ameaça de extinção do Conselho Nacional de Desenvolvimento Científico e Tecnológico (CNPq) por falta de provimento de verbas para equilibrar seu orçamento; e) corte ou suspensão do provimento de verbas para as universidades federais; f) transferência indireta dos custos de financiamento da pesquisa, como projetos e bolsas , para as gestões das instituições de Ensino Superior federais e/ou estaduais.

As ações acima listadas permitem a inferência de que estamos diante de um projeto que visa acabar com as políticas de inclusão e de expansão da Educação Superior, iniciadas nos governos progressistas e no desmonte do papel do Estado na Educação Superior.

A expansão das universidades federais e estaduais ocorreu num contexto dominado pelas políticas de inclusão implementadas pelo governo do PT, que reconfigurou o mapa da esfera pública e privada através de programas que deram sustentabilidade às políticas de inclusão. Os programas PROUNI e REUNI constituíram, nesse contexto, programas de acesso ao Ensino Superior.

A recuperação do estado atual na estrutura do Ensino Superior brasileiro pode demorar décadas, e assim assistimos a um novo ciclo de ataque à educação pública e à Educação Superior, ciclos que se relacionam diretamente com a intensa proximidade com o modelo neoliberal, só que desta vez, exposto na sua versão mais retrógrada, ultraconservadora e religiosa, se é que é possível, estabelece uma categoria de retrocesso social e político nos modelos neoliberais.

\section{Notas}

1. Formada por um pequeno grupo de pessoas que "comanda os grandes bancos e os fundos de investimento. É em ela que as outras frações de endinheirados, como a fração do agronegócio, da indústria e do comércio, confiam seu lucro" (Souza, 2016, p. 13).

2. Destaque-se que o Brasil é o único país da região onde não existe "mídia pública", e quem ostenta o privilégio das concessões estatais são os grupos privados que mantém refém os governos e sua capacidade de comunicação direta com a população sobre o Estado, em ação e nas políticas públicas. A demonização política do Partido dos Trabalhadores, que resultaria na eleição de Bolsonaro, se deve à existência deste modelo de relação entre Estado e mídia privada. Os conglomerados de mídia e comunicação na região fecharam um acordo em 2004 para tirar governos progressistas da região, fato que ocorreria quase uma década depois (Ver https://www.worldcces.org/article-2-by-enrique-aguilar/states-and-fragile-democracies-in-latin-america-comparative-analysis-on-institutional-power-and-power-in-fact).

3. "O nome do caso, "Lava Jato", decorre do uso de uma rede de postos de combustíveis, e lava a jato de automóveis, para movimentar recursos ilícitos pertencentes a uma das organizações criminosas inicialmente investigadas. Embora os trabalhos tenham avançado para outros rumos, o nome inicial se consagrou. 
No primeiro momento, foram investigadas e processadas quatro organizações criminosas lideradas por doleiros, que são operadores do mercado paralelo de câmbio. Depois, o Ministério Público Federal recolheu provas de um imenso esquema criminoso de corrupção, envolvendo a Petrobras" (http://www.mpf.mp.br/grandes-casos/lava-jato/entenda-o-caso/entenda-o-caso).

4. Um tipo de manobra contábil feita pelo Poder Executivo para cumprir as metas fiscais, fazendo parecer que haveria equilíbrio entre gastos e despesas nas contas públicas. Ressaltamos que tal desequilíbrio era temporário uma vez que a União equilibrava as contas, repondo os valores transferidos de uma conta para outra dentro do exercício fiscal.

5. Trata-se do conjunto de entidades privadas vinculadas ao sistema sindical patronal responsável de aplicar recursos na formação profissional e na prestação de serviços sociais aos trabalhadores. As entidades são mantidas pelas contribuições e pagas compulsoriamente pelos empregadores, que incidem sobre a folha de salários com alíquotas variadas. O sistema S está previsto na Constituição de 1988.

6. Trata-se de ação quando o governo bloqueia a execução de parte do orçamento devido à previsão da diminuição das receitas advindas dos impostos e tributos.

\section{Referências}

Aguilar, L.E. (2017). States and fragile democracies in Latin America: comparative analysis on institutional power and power in fact. World Voices Nexus - The WCCES Chronicle, 1(1), 1. Recuperado de https://www.worldcces.org/article-2-by-enrique-aguilar/states-and-fragile-democracies-in-latin-america-comparative-analysis-on-institutional-power-and-power-in-fact.

Agostini, R. (2019). MEC cortará verba por "balbúrdia” e já enquadra UnB, UFF e UFBA. O Estado de São Paulo. 30 de abr. Disponível em https://educacao.estadao.com.br/noticias/geral,mec-cortara-verba-de-universidade-por-balburdia-e-ja-mira-unb-uff-e-ufba,70002809579.

Baquero, M. (2008). Democracia formal, cultura política informal e capital social no Brasil. Opinião Pública, 14(2), 380-413. https://doi.org/10.1590/S0104-62762008000200005.

Despacho. Superior Tribunal de Justiça. Ministro Sérgio Kukina. Recuperado de https://www. conjur.com.br/dl/ministro-nega-pedido-suspender-corte.pdf.

Morlino, L. (2007). Explicar la calidad democrática: ¿qué tan relevantes son las tradicionales autoritarias?. Revista de ciencia política (Santiago), 27(2), 3-22. https://dx.doi.org/10.4067/ S0718-090X2007000300001

O’Donnell, G. (1991) Democracia delegativa?, Novos Estudos CEBRAP, n. 31, out.

O’Donnell, G. (2009). La Democracia Delegativa. Diario argentino La Nación, 28 de maio de 2009. Disponível em: http://www.lanacion.com.ar/1429892-la-democracia-delegativa.

Portal MEC (2011). Programas de expansão fazem crescer acesso às universidades. Ministério da Educação. 30 abr. Disponível em http://portal.mec.gov.br/ultimas-noticias/212-educacao-superior-1690610854/16526-programas-de-expansao-fazem-crescer-acesso-as-universidades.

Quijano, A. (2005). Colonialidade do poder, eurocentrismo e América Latina. In: Lander, E. (2005). A colonialidade do saber: eurocentrismo e ciências sociais. Perspectivas latinoamericanas. (Júlio César Casarin, Trad). Buenos Aires, Colección Sur Sur, p. 118-142.

Saldaña, P. (2019). Com nome de Operação lava jato da educação ainda é protocolo de intenções. Folha de São Paulo, 18 mar. Disponível em https://www1.folha.uol.com.br/educacao/2019/03/ com-nome-de-operacao-lava-jato-da-educacao-ainda-e-protocolo-de-intencoes.shtml.

Souza, J. (2016). A radiografia do golpe: entenda como e por que você foi enganado. Rio de Janeiro: Le Ya.

Souza, J. (2019). A elite do atraso. Rio de Janeiro: Educação Brasil.

Brasil, Tribunal de Contas da União (2014). Relatório e parecer prévio sobre as contas do governo e da República. Brasília. Ministro Augusto Nardes, Relator. Recuperado de https://portal. tcu.gov.br/data/files/27/72/33/90/AE260510711B85052A2818A8/Relat_rio\%20e\%20 Parecer\%20Pr_vio.pdf. 